\title{
GIS for Pandemic Zoning: Application of Brampton, Ontario, Canada
}

\author{
Roland Daley ${ }^{1}$, Flor Ferreras ${ }^{1}$, John Orly ${ }^{1}$, Rifaat Abdalla ${ }^{2, *}$ \\ ${ }^{1}$ Disaster and Emergency Management Graduate Program, Faculty of Graduate Studies, York University, Canada \\ ${ }^{2}$ Department of Hydrographic Surveying, Faculty of Maritime Studies, King Abdulaziz University, Saudi Arabia
}

Copyright (C) 2015 by authors, all rights reserved. Authors agree that this article remains permanently open access under the terms of the Creative Commons Attribution License 4.0 International License

\begin{abstract}
This paper examines the use of Geographic Information System (GIS) in mass casualty zoning for a pandemic in the city of Brampton, Ontario. Canadians in general are familiar with the SARS outbreak in 2003 and the effect that it had on medical care facilities, human resources, and national economy. In the year of 2009, Canadians were faced with another pandemic, the H1N1 influenza. These pandemics created widespread panic among many residents and the lessons learned is that health officials need to effectively plan for another outbreak. Focusing on Brampton as one of the western cities in the Greater Toronto Area (GTA) in the Province of Ontario, Canada; where there is urbanization and concentration of population served by one main medical health facility, i.e., Brampton Civic Hospital. This research examined the capacity of current facility to deal with emergency surge. Specifically, where there is a need for large number of health care professionals to deal with emergency situations. The paper provides a model for emergency management professionals to utilize GIS as a decision-making tool in assessing the risks, tracking outbreaks, maintaining situational awareness, during pandemic outbreaks. It provides analysis of means and ways for minimizing disruptions which may occur in a community.
\end{abstract}

Keywords Disaster $\quad$ Management, Pandemic,
Visualization, Casualty

\section{Introduction}

In this era of mass travel many travelers pass through Canada's Pearson International Airport and many people use the Toronto Transit Commission (TTC) subway system to connect to places all over. With this pattern of travel, it is quite easy for travelers to get infected with a strain of influenza from foreign countries and travel to Canada with the virus. Due to the close contact that passengers share as they travel it is easy for influenza to spread from person to person before any symptoms develop. With the spread of the disease, many residents will get sick which will undoubtedly put a strain on healthcare facilities, human resources, and the healthcare system.

Brampton is a western community in Ontario with approximately 433,806 residents and one that is rapidly growing. Many of these residents travel outside their community to Toronto to work or attend school. However, it is the belief that when there is a pandemic outbreak, and the residents of Brampton get ill, it is natural that they are going to seek healthcare in their area of residence. The issue with residents seeking healthcare need in their area of residence is that Brampton has only one primary healthcare facility; Brampton Civic Hospital, and the predicted rate of spread of the disease on a daily basis will be too much for this one hospital to handle.

Being knowledgeable about the SARS and H1N1 pandemic that affected Canada in 2003 and 2009 respectively, as emergency management professionals will effectively use GIS software, which is widely used as a decision-making tool in emergency management to enable officials to plan and respond to another possible pandemic outbreak in Brampton. In doing this research, the research question asked is how emergency management professionals can effectively prepare and respond to the next pandemic in the community of Brampton using GIS as the decision-making tool with as little disruption in the economy as possible?

\section{Background}

Pandemics put more pressure and complicates national socio-technical systems Atkins et. al [1]. The residents of the city of Brampton, which is the focus community for this project, will also be affected once there is a pandemic outbreak.

The interaction between biological and socio-technical systems is known as (BIST) Barrett et. al [2].Many researchers including Chirsitan, et. al [3] and Chulmin et al [4] have investigated the issue of providing accessible public 
health systems during emergencies. GIS is an effective tool for mapping and visualization of spatial models Chrisman [5], Cromley et. al [6] and Eubank et al [7]. The utility of GIS in pandemic zoning has significantly developed with the development in technology Faruque et al [8], Ghose et al [9] and Lin et al [10]. The issue of mass causality analysis using GIS has helped with identifying hotspots of impact and determination of evacuation routs and isolation centers in many pandemics. Medici et al [11], they determined that: "particularly weak was a detailed process for dealing with significant numbers of fatalities over cyclical periods of weeks to months" when dealing with mapping the temporal aspects of pandemics over extended spatial extent. Similar concept of GIS-based risk assessment was used by Mekni et al [12] and Miller, H. [13] to investigate spatially sensitive risk zones for accidents in tracks. The track of pandemic dynamics and spread was further investigated by Perez et. al [14], Peel Public Health [15]. The predication of outbreak spread of pandemics was the subject of research for many researchers, including Tachiiri [16] and Schull [17], who found that GIS is effective mechanism in decision support for pandemic prediction and hospital capacity management during outbreaks. Wilkins [19] was able to develop a model that accounts for population in the process of outbreak monitoring and control using spatiotemporal information.

Pandemics are spreads of infectious disease around human pollutions leading to increasing number of deaths. They have been around for centuries and are known worldwide, the effort was taken into consideration by international organizations, WHO [20], and public voluntary organizations, the Whole of Society Pandemic Readiness [21]. Historically, pandemics have been reported in different parts of the world, including the recent Ebola spread in West Africa in 2015. The urbanization and interconnectedness of communities contribute significantly to the spread of diseases. In this age, there are well known pandemics such as AIDS HIV, Cholera, Yellow Fever, and Tuberculosis.

According to Noe et al [22] the three pandemics that occurred during the 20th century were in the years: 1918 1919 (Spanish Flu), 1957 - 1958 (Asian flu), and 1968 -1969 (Hong Kong Flu). Health Canada (2008) reported that the deadliest being the 1918 -1919 Spanish Flu which was said to have claimed the lives of $40-50$ million people worldwide.

Recent outbreaks of SARS in 2003 and H1N1 in 2009 shows how the healthcare system is vulnerable to such events and how fast it could crumble with the weight of the number of cases that will need immediate, prolonged and advanced care. During pandemic outbreaks, public health organizations are stretched by multiple demands. They must coordinate activities with many partners, report to governing bodies, and communicate with the public. Absenteeism among healthcare personnel is very likely as many of them may take off from work in order to care for their sick loved ones or because they are also ill.

According to the Ontario Health Pandemic Plan, 2008
[23], "During pandemics, vaccine for pandemic influenza will not be available for four to six months following the identification of the pandemic virus and will not be available for the first and possibly the second wave. Once vaccine is available it will be initially in short supply and high in demand" (Ontario Health Pandemic Plan, 2008). As per Christian et al, [3], "It is predicted that hospital admissions for influenza will peak at 1823 per day over a 6 -week period. This translates to $72 \%$ of the total hospital capacity being used by influenza patients. Similarly, the demand for intensive care unit (ICU) resources solely for patients with influenza would peak at $171 \%$ of current ICU bed capacity and $118 \%$ of the ventilator capacity. These figures do not take into account the current usage rate of critical care for patients without influenza, which is nearly at $100 \%$ nor does this factor in the availability of human resources. With these predictions in mind, community-based disease control strategies will have to be implemented in order to try to slow down the transmission of the virus. Many restrictions such as closure of schools, childcare centers and restriction of large public gatherings such as concerts will have to be implemented. It is said by ESRI, 2009 that, "Around the world, public health organizations at all levels of government and the partners that support them are responding to pandemic influenza. Infectious disease experts predicted a pandemic, saying it was not a question of if but when" Chrisman et al [3]. GIS is powerful software that is being widely used as a decision making tool in different areas of emergency management and so as emergency management professionals will be applying GIS knowledge to effectively plan for the next pandemic outbreak.

Pandemics are known worldwide and historically have been reported in different parts of the world, including the recent Ebola spread in West Africa. The urbanization and interconnectedness of communities contribute significantly to the spread of diseases.

\section{Study Area}

The area of study was on healthcare and the possible outbreak of pandemic in the GTA with a focus on Brampton. The hospital included in this study is the Brampton Civic Hospital, which is the only primary healthcare facility in Brampton, and it is located at 2100 Bovaird Ave, Brampton Ontario. (Fig 8). Peel Public Health [15].

Brampton Civic Hospital is the newest in the William Osler family of hospitals and was opened in October 2007. It is said that the hospital has already made its mark on the communities that it served and on healthcare in Ontario. Demand for services at Brampton Civic has grown significantly since its opening with patient volumes nearly 30 per cent higher than what was projected prior to the hospital's opening. The hospital is slated to grow to 608 beds - its actual capacity - within the next one to two years as demand for health services in the area continues to grow. The hospital is also one of Brampton's largest employers: just 
under two-thirds of Osler's 4,100 employees work at Brampton Civic. An additional 600 people provide non-clinical support services through contracted partners (William Osler Health Center).

Brampton is an area of approximately $265 \mathrm{~km}^{2}$ with a population of about 433,806 residents. Brampton is situated on the western side of Ontario and is said to be the third largest city in the Greater Toronto Area (GTA) and the 11th largest city in Canada. (See Fig 2)

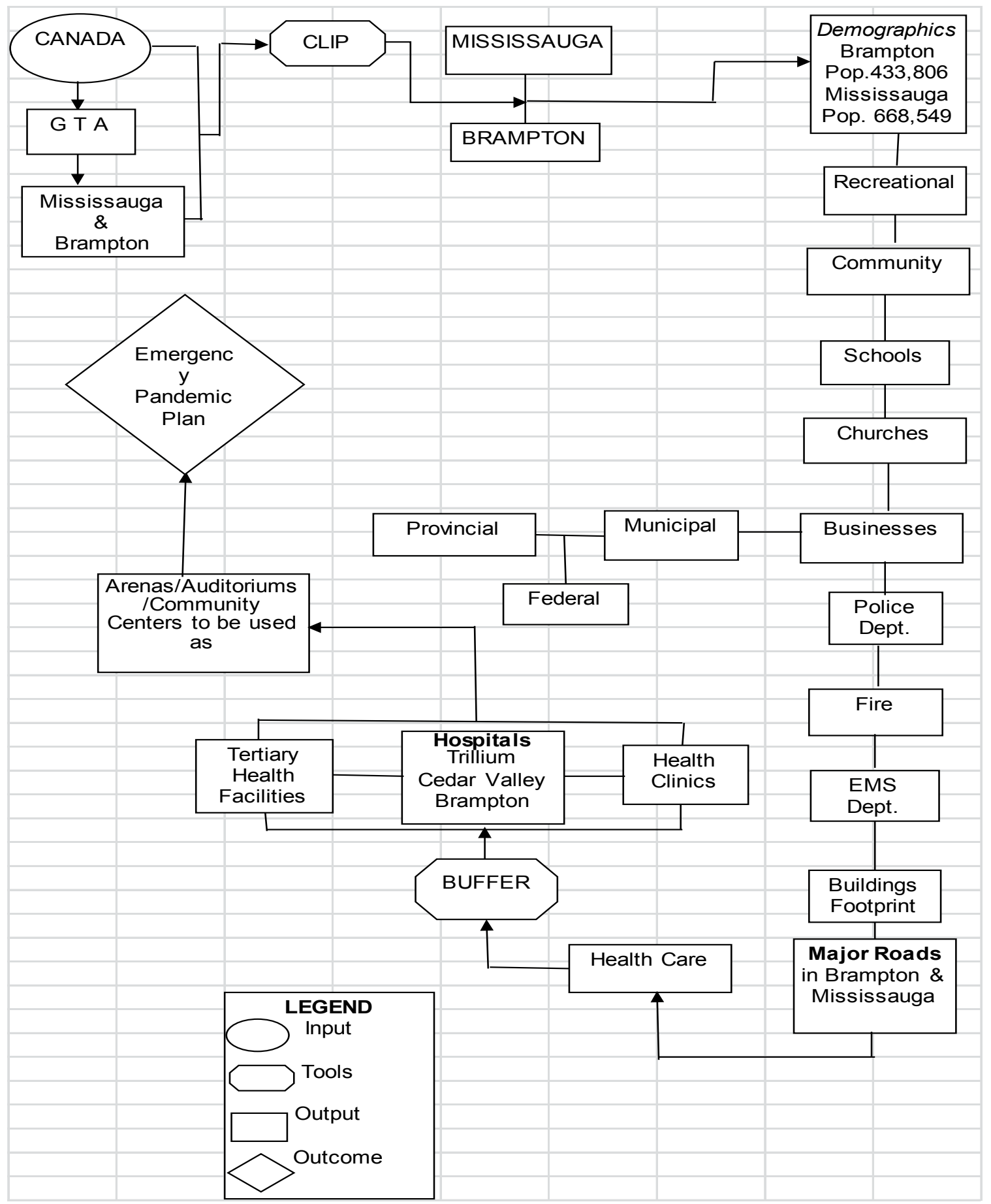

Figure 1. Proposed Cartographic Model 


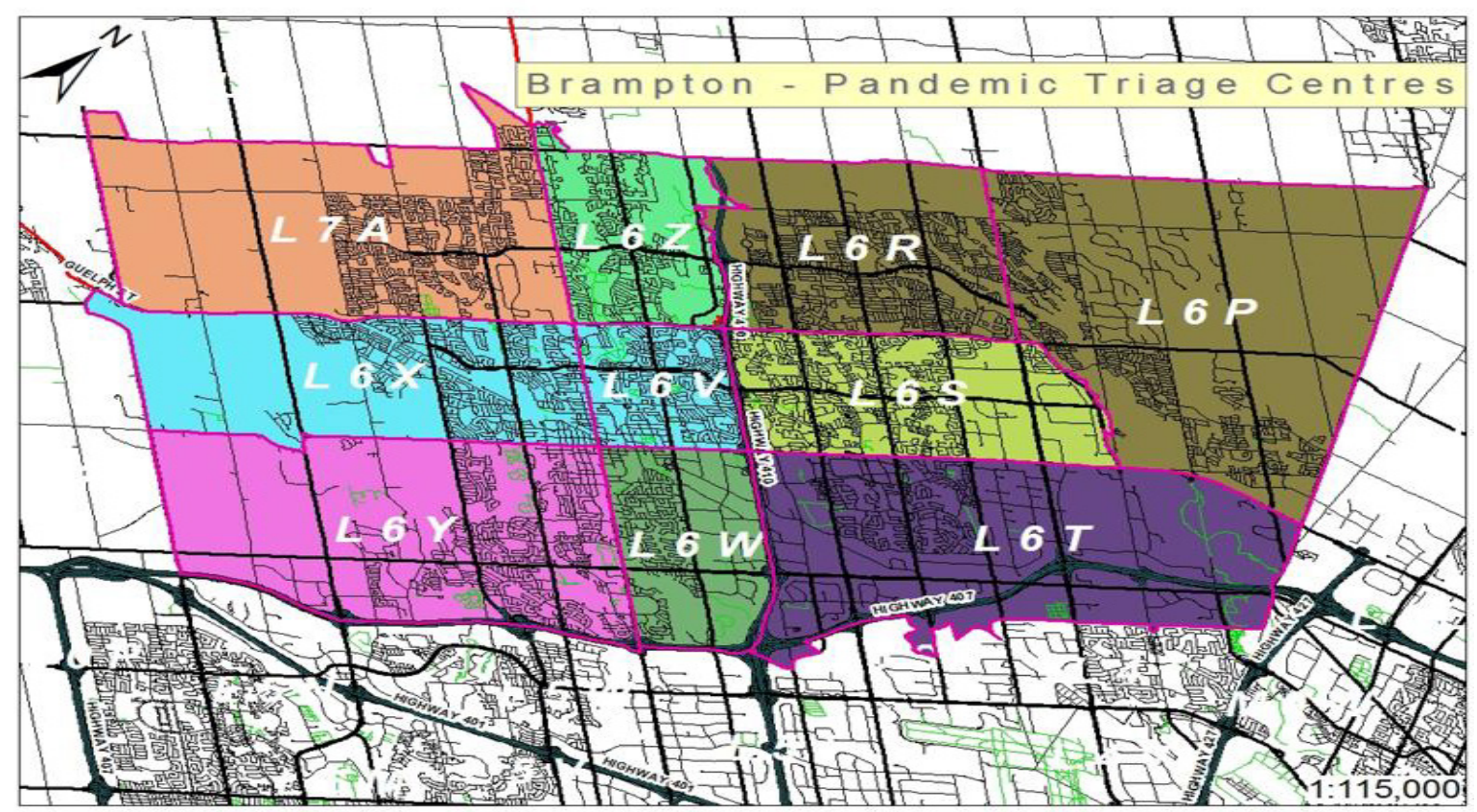

Figure 2. Zoning of the city of Brampton using polygons Based on Postal Code (No Layers)

For this study, the focus was placed on the seven recreational centers found in Brampton and the location of the old hospital. Therefore, the following centers were proposed: (Fig 8)

Terry Miller Recreation Centre, 1295 Williams Parkway, positioned at Longitude 79.73059W, Latitude 43.73315N setup in the zone of L6S.( Fig 4)

Chinguacousy Wellness Centre, 995 Peter Robertson Boulevard, positioned at Longitude 79.74297W, Latitude 43.75016N setup in the zone of L6R and L6P. (Fig 4)

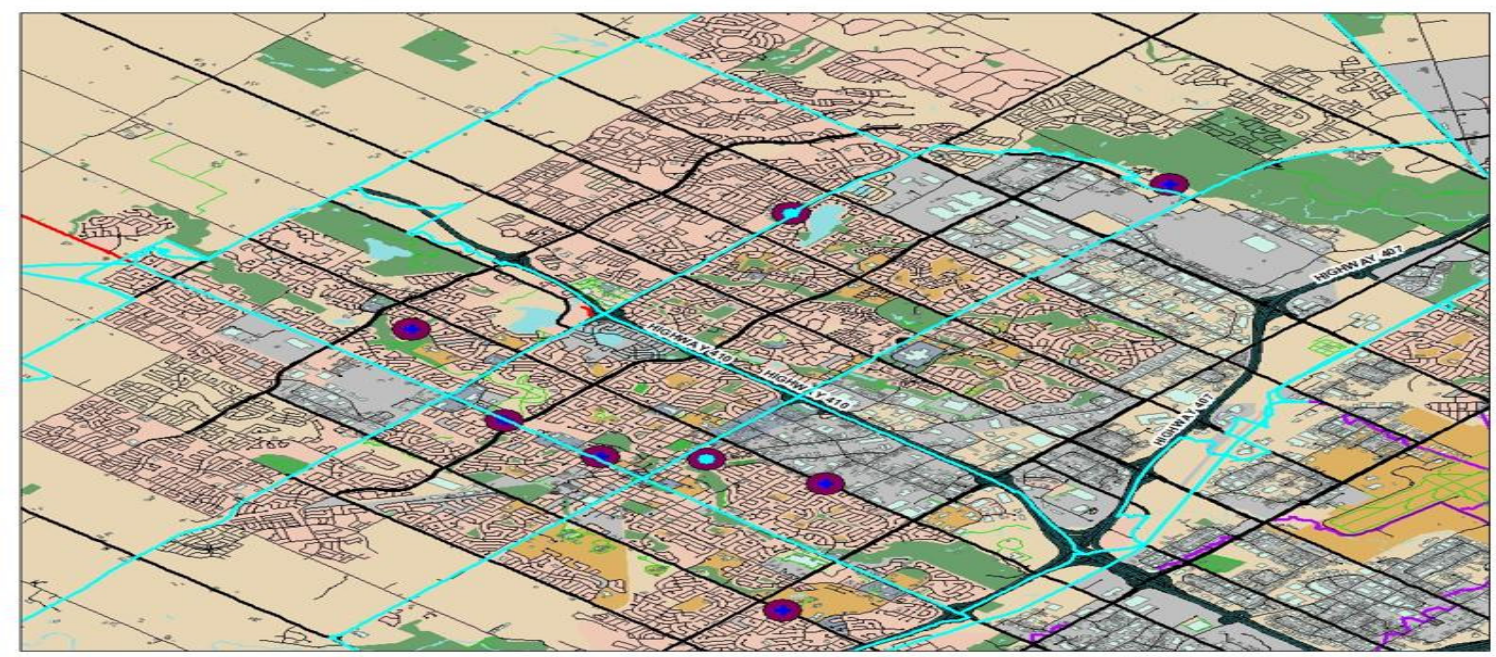

Figure 3. City of Brampton-Layout of Residential Areas and Streets 


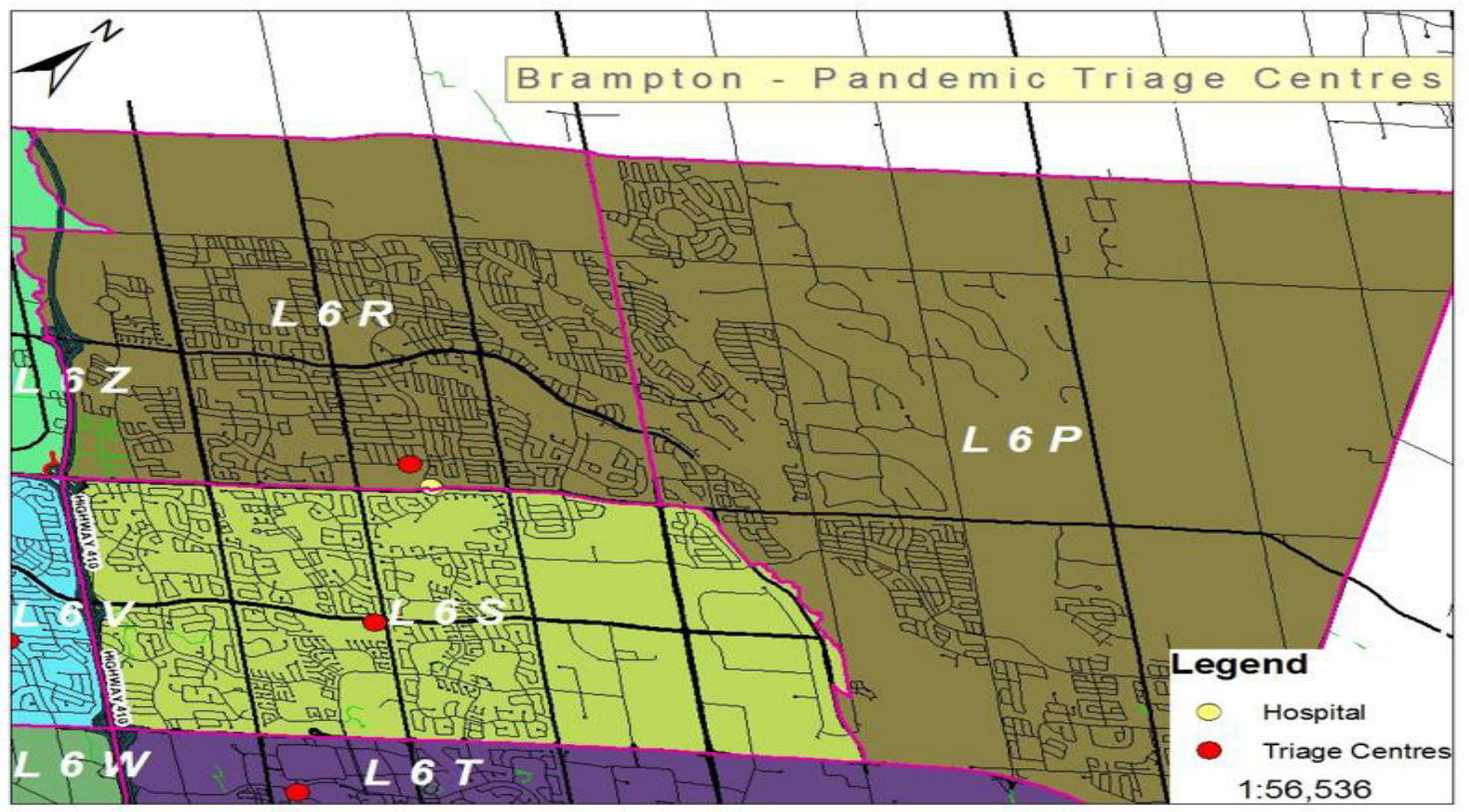

Figure 4. Brampton NE Triage Centers

Century Gardens Recreation Centre, 340 Vodden Street East, positioned at Longitude 79.75370W, Latitude 43.70854N setup in the zone of L6V and L6X.(Fig 5)

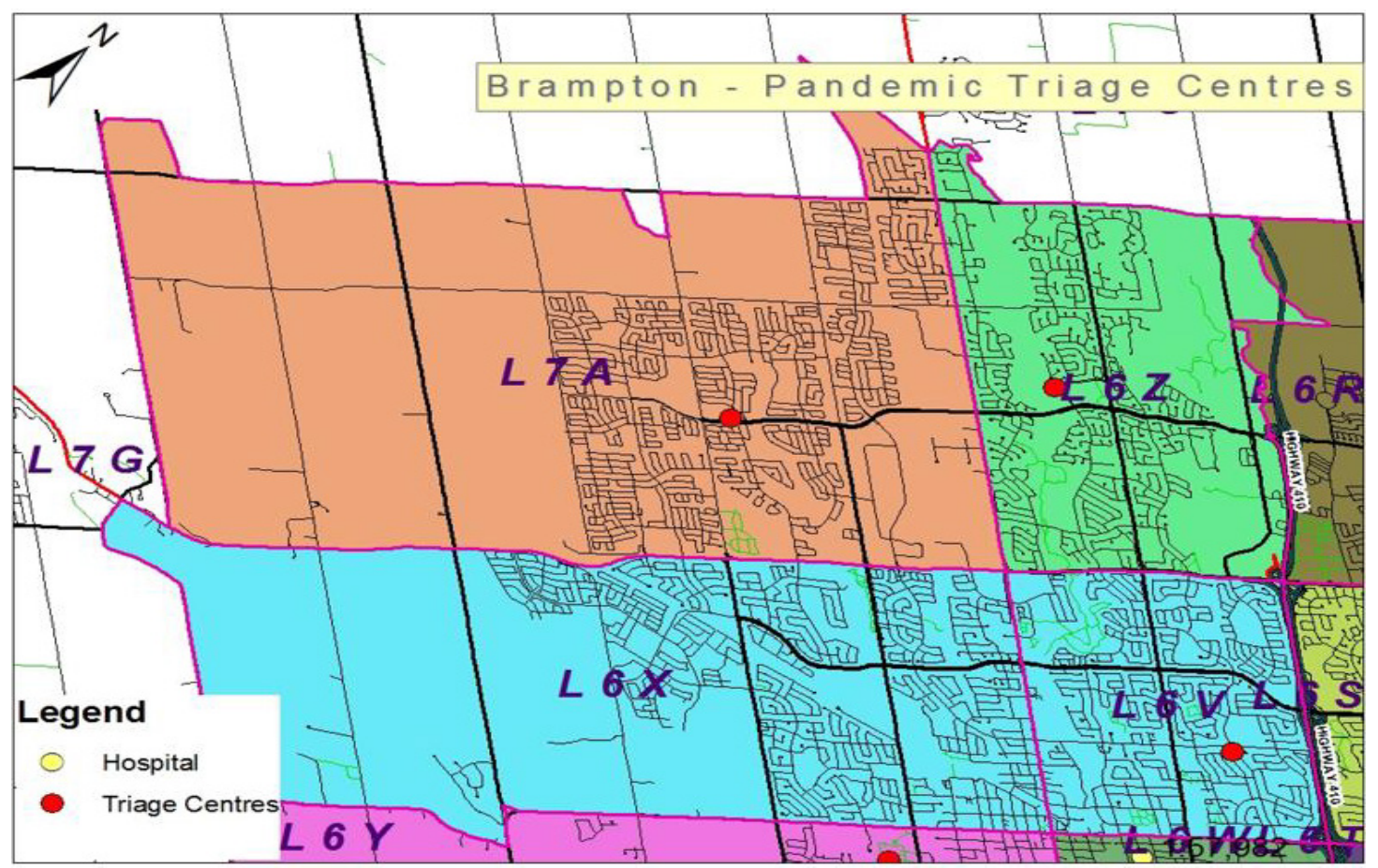

Figure 5. Brampton NW Triage Centers 


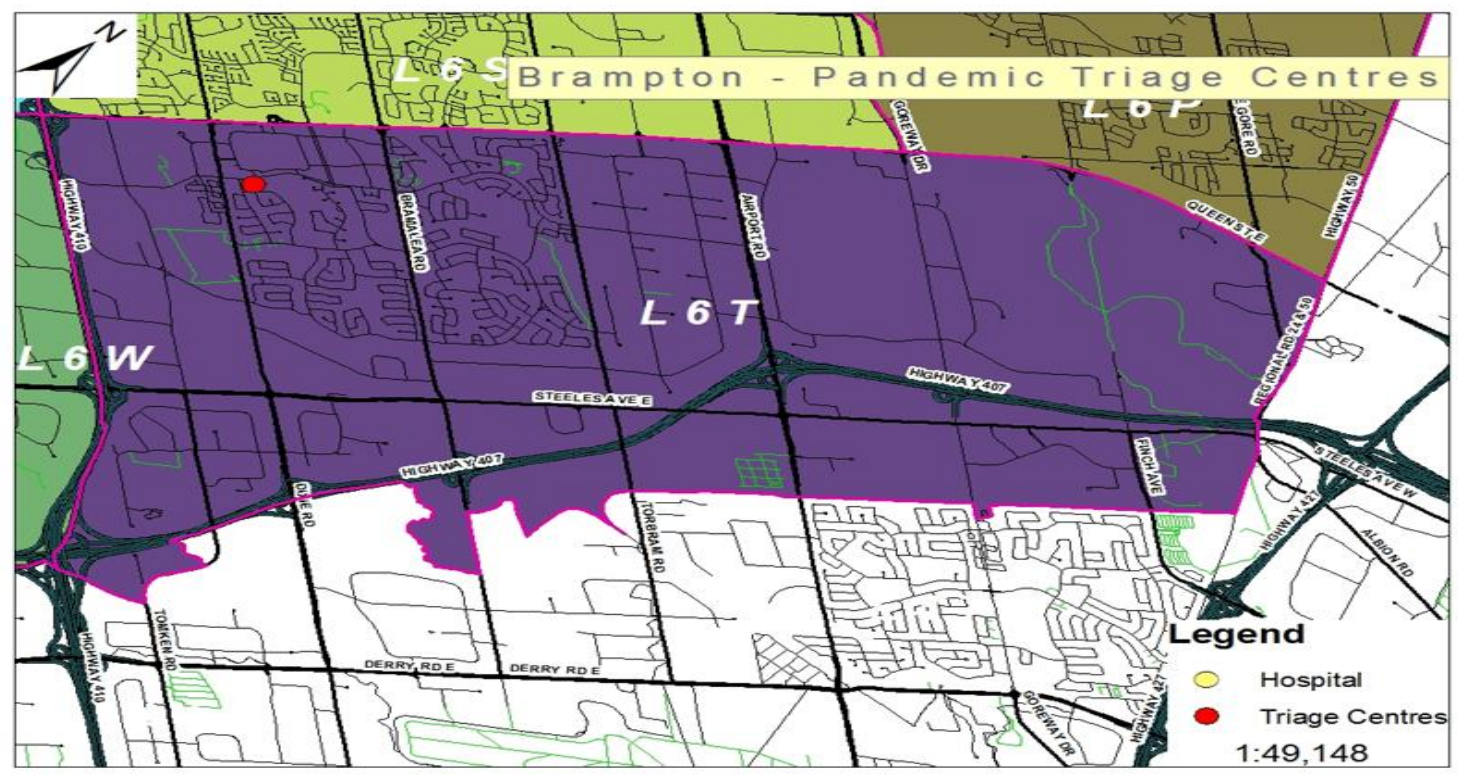

Figure 6. Brampton SE Triage Centers

Flower City Seniors Recreation Centre, 8870 McLaughlin Road, positioned at Longitude 79.76958W, Latitude 43.67136N in the zone of L6Y. (Fig 7)

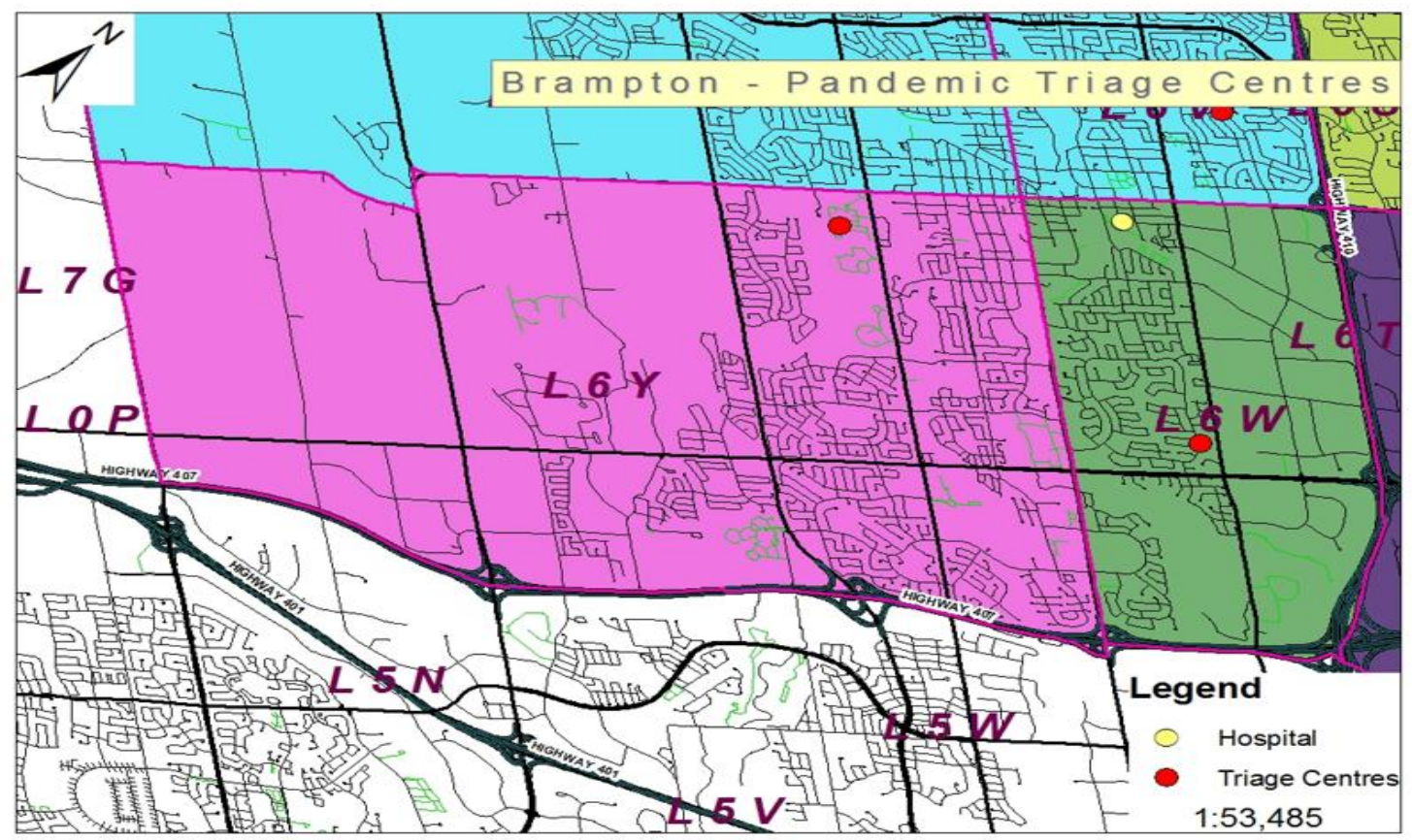

Figure 7. Brampton SW Triage Centers 


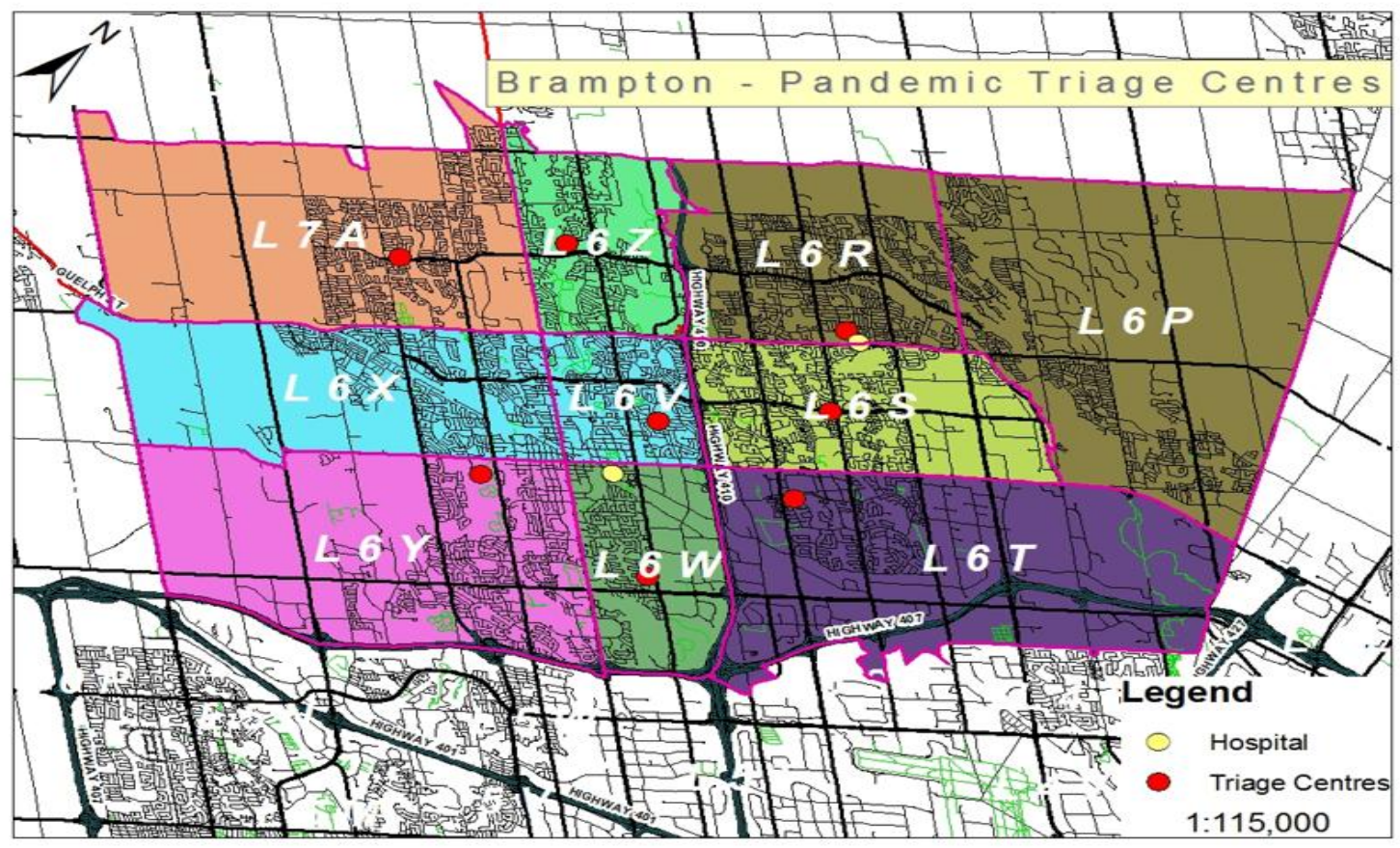

Figure 8. Completed Zoning of Hospitals and Triages Centers

Ken Giles Recreation Centre, 364 Bartley Bull Pky, positioned at Longitude $79.72704 \mathrm{~W}$, Latitude $43.67684 \mathrm{~N}$ in the zone of L6W.( Fig 6)

These recreational centers are used for triage centers based on the scope of the project. (Fig 2)

\section{Methods and Data}

GIS for Emergency Management has been well known for many years now. Abbas et al [24] ESRI [25] and Goodchild [26] For the purpose of conducing this research, the authors have obtained the DMTI data with the map of Ontario and then use ArcGIS ArcMap and ArcCatalog to work with the data. From the data a layer was created which represents the City of Brampton. Being unable to get data for only Brampton and not able to clip it from the data. It was possible to analyze how best the map can be displayed.

It was possible to select and highlight the area of Brampton by activating the street layer. With this done it was possible to add spatial data which are the healthcare facility and recreational centers. Since the data we received for Ontario only gave generic buildings. It was possible to locate recreational centers which would be used as triage centers. This was achieved by researching the X Y coordinates for these buildings, creating an excel sheet and then create a shapefiles which were imported into map as a layer. Attribute data were attached to recreational centers as it could be seen in the postal codes that governs them and the major roads close to where they are located.

\section{Results and Discussion}

Many researchers have dealt with the concept of hazard risk assessment for Emergency Management including Gordon [26]. The spatial analysis capabilities for GIS can be used in diverse types of risk assessment and emergency preparedness, Jaiswa et. al [28]. Longley et. al. [29] has discussed the foundations of using GIS for solving real-world problems. The methodology to create the GIS map was developed after careful analysis of the data available, ease of reading the map and limitations of knowledge of the group and time available, Prizzia [30]. A logical and simple approach was developed to present this research in a comprehensive way Kwan et. al. [31] using combination of basic geospatial data and basic analysis of what layers will be required to accomplish the required outcome.

At the outset of the project was looking at developing the pandemic triage centers network for the area of Brampton, Mississauga and Oakville - three major bedroom community centers in Ontario. However, after analyzing the GIS raw data of the study area and after an extensive publication research to substantiate the project, it was decided to narrow the scope of the project to the city of Brampton. Working with all three cities at once or even with two (it was briefly considered including Brampton and Mississauga in the map development) became too broad and cumbersome. Limiting the project extent of interest to the city of Brampton only allowed for an easier GIS data management, better understanding of the processes and much more enhanced visual outcome of the final product.

Working with the dataset of Ontario created an issue with ability to process large volume of data by the computer every time the map was needed to be reloaded. Initial display of the map of Ontario was zoomed in to display city of Brampton 
and a number of layers was deactivated in order to lower the amount of data required the computer to process. The layers that were used were: 1) Healthcare Centers, 2) Highways, 3) Roads and Streets, 4) Residential and Industrial Area Indicators, 5) Education Facilities, 6) Building Footprints and 7) Postal Code Areas.

Once the data was reduced to more manageable level the analysis of suitable locations for the pandemic triage center network was performed. Initially the Community Center buildings were considered, however, lack of data put this solution on hold.

Next, education facilities were considered, since the data was already included with the layer, it was a tempting avenue to take. However, further analysis of the circumstances of the scenario under consideration, the spatial position of the location of the facilities and conclusions drawn from that did not allow us to recognize this as a viable option. After all, it was not possible expect that the educational system would shut down for the duration of the pandemic, which could last weeks or even months. It was not possible to be able to utilize education buildings while they are being used for schooling.

After the analysis of the alternatives to setup the triage centers; the other healthcare facilities already included in the dataset provided by the Healthcare Centers layer - namely Senior Houses. As much as this choice would have been easy to implement as a number of such facilities is already present in that there are not enough of such facilities to service close to 450,000 residents of Brampton. Second, it would not be prudent from the healthcare point of view to bring sick population for triage into the close proximity of one of the most vulnerable residents of the city - the seniors. This has led to the acceptance this alternative.

The spatial and practical suitability of the smaller healthcare facilities in Brampton was analyzed, such as walk-in clinics and doctor's clinics. Information was gathered on a number of those and started plotting them on the map to see where they are located and what type of buildings they occupied - building footprints were assessed in this case. It was not possible to determine through analysis that either the buildings or the facilities were big enough for the task. Most of these healthcare facilities were small doctor offices occupying single office units or small buildings at best. Again, it was possible to determine after careful analysis of the geospatial data and the information about the facilities that those were not enough to handle large crowds of affected seeking healthcare help. While analysis of the last option was rejected, it was reverted to the original one, of selecting number of community centers strategically located throughout the city. An idea of adding to triage network two other facilities was developed. One of them is William Osler Health Centre - Peel Memorial Campus that was closed for redevelopment in October 2007and the other is William Osler Health Centre - Brampton Civic Hospital. It was decided to incorporate the first one as an isolation unit in case the healthcare authorities decided to implement the isolation into the pandemic response process. The second one, with all its equipment and staff would be utilized as the ICU. The Healthcare Facilities layer was used to select and highlight both facilities on the map after which it was possible to isolate these two items and create the layer with only those two attributes to lower the need for data processing, since it was possible to remove the layer containing all data from entire Ontario.

Furthermore, the following layers were removed: Building Footprints and Education Facilities. The suitability of Community Centers' capability to handle large numbers of patients affected by the pandemic was further investigated and analyzed. The data such as building sizes, and capacities as well as geographical coordinates was obtained, which has helped with plotting their locations on the map of Brampton and determine their suitability. Due to the nature of the facilities their location is more or less in the central area of the city. After analysis it was determined that a facility in the North-eastern part of the city was missing in the scene. However, it was replaced with one of the healthcare facilities (Public Health Clinic at the Brampton Civic Centre) as one of the Triage Centers. A total of eight facilities were chosen to act as Triage Centers. The analysis of their localization suitability was based on the density of the Residential Areas throughout Brampton. Once their location was plotted based on geographical coordinates, it was considered buffering the applicable zones belonging to each and every one of them. Using the buffering feature of ArcGIS the two facilities were buffered first at 2 and then at $5 \mathrm{~km}$. The output was analyzed and noticed in both cases that buffering will not be a suitable way for zoning. It was simply to inclusive and overlapping, because there was no control over where the potential Triage Centers are (i.e. how far from each other), as it was not possible to control the rate of overlapping of the buffered zones. It was decided that this was not acceptable outcome.

Another way to create the zones was to use the Postal Code layer to zone the sections according to the postal code's first three characters. This became possible by obtaining a list of postal codes in Brampton. The output product of this function became a one triage facility per postal code zone (in two instances there is one triage facility assigned to two postal code zones). It was considered assigning triage centers based on the population density, however, available data and ability of the team to build such a complex and advanced spatial data attribute layer, became a task beyond the scope of this course and project. Eventually the layer of triage centers was developed based on the residential areas street densities.(Fig 3) Using published literature on pandemic, disaster and emergency management skills, and gained GIS knowledge, It was possible to be able to create a pandemic model for the city of Brampton. In order to validate the model and highlight recreational centers and healthcare facility that is spatially valid in the city of Brampton. In addition, the model provides a viable alternative for emergency management officials seeking effective means of preparing and responding to the next possible pandemic outbreak in Brampton. Because it was possible to locate all the recreational centers that could be used for triage centers, 
this would limit the use of the Brampton Memorial Hospital for treating those patients that require ventilators and long term medical care. In addition, with the eight recreational centers located across the city, residents would be able to access these centers easily depending on the postal code in which they are residing. In addition, these centers are located close to major roads, which make it easy for residents, ambulances and other emergency vehicles to access these facilities.

The greatest limitation encountered with respect to following the stated research approach is the fact that working with the entire data for Ontario and was not able to clip Brampton and Mississauga, which were the two communities were initially planned on doing for this project. Realizing this was an issue with data as there was no other alternative than to concentrate on just Brampton. However, by working with the one community, it was possible to experience the power of GIS and its application to single area of pandemic planning.

\section{Conclusions}

This research provides a solution for similar problems for other communities faced with similar situations. GIS has created effective decision support mechanisms that is significant to decision-makers to assess risk, evaluate threats, and help minimize disruptions. This research has allowed providing cutting-edge solution that helps emergency management officials with real scenario for planning for future pandemics in the GTA.

GIS is proven to be effective with planning emergency management solutions related to pandemics, and is applicable to every spatial entity that is related to the City of Brampton. This research posed various challenges related to data and information management, which are crucial for decision-makers and technical staff dealing with emergency management.

\section{REFERENCES}

[1] Atkins, K., Barrett, C. L., Beckman, R., Bisset, K., Chen, J., Eubank, S., Feng, A., Feng, Z., Harris, S. D., Lewis, B., Anil Kuman, V. S., Marathe, M. V., Marathe, A., Mortveit, H., Stretz, P. (2008) ."An Interaction Based Composable Architecture for Building Scalable Models of Large Social, Biological, Information and Technical Systems," CTWatch Quarterly, Volume 4, Number 1

[2] Barrett, C., Eubuank, S., Marathe, M. (2005). "Modeling and Simulation of Large Biological, Information and Socio-Technical Systems: An Interaction Based Approach," in Interactive Computation: The New Paradigm, D. Goldin, S. Smolka and P. Wegner Eds. Springer Verlag.

[3] Christian, Michael D. ; Hawryluck, Laura; Wax, Randy S.;
Cook, Tim ; Lazar, Neil M; Herridge, Margaret S.; Muller, Matthew P.; Gowans, Douglas R.; Fortier, Wendy and Burkle, Frederick M.(2006). "Development of a Triage Protocol for Critical Care during an Influenza Pandemic". Canada Medical Association Journal (CMAJ) Nov. 21

[4] Chulmin Jun. (2000). "Design of an Intelligent Geographic Information System for Multi-criteria Site Analysis". URIS Journal Vol. 12 (13),5-17

[5] Chrisman, Nicholas R.; "Fundamental principles of Geographic Information Systems" Department of Landscape Architecture, University of Wisconsin-Madison, Madison, WI

[6] Cromley, Ellen K. (2003). "GIS and Disease" Annual Review of Public Health, Vol. 24: 7-24

[7] Eubank, S., Guclu, H., Anil Kumar, V. S., Marathe, M., Srinivasan, A., Toroczkai, Z., Wang, N. (2004). "Modeling Disease Outbreaks in Realistic Urban Social Networks," Nature, 429, pp. 180-184.

[8] Faruque, Fazlay S.; Lofton, Susan P.; Doddato, Theresa M.; and Mangum, Carl.(2003). "Utilizing Geographic Information Systems in Community Assessment and Nursing Research", Journal of Community Health Nursing, 20(3), 179-191

[9] Ghose, Rina; "Use of Information Technology for Community Empowerment: Transforming Geographic Information Systems into Community Information Systems." Department of Geography-Geology, Illinois State University, Normal, IL

[10] Lin, Ge; Allan, Diane E. and Penning, Margaret J. (2002)."Examining distance effects on hospitalizations using GIS: A study of three health regions in British Columbia, Canada". Environment and Planning, volume 34, pages 2037 $-2053$

[11] Medici, John E. \& Simms, David J. (2007). "Mass Casualty Data Management System (From Complaint to the Grave)". ESRI Conference. Retrieved January 28, 2010

[12] Mekni, Mehdi; Sahli, Nabil; and Moulin, Bernard. (2008) “ A Geosimulation Approach Involving Spatially-Aware Agents A Case Study on the Identification of Risky Areas for Trains" SpringSim, 8 pages

[13] Miller, Harvey J.; "Potential contributions of spatial analysis to Geographic Information Systems for transportation (GIS-T)" Department of Geography, University of Utah, Salt Lake City, UT Forthcoming in Geographical Analysis (30th anniversary issue)

[14] Perez, Liliana and Dragicevic, Suzana. (2009). "An Agent-based Approach for Modeling Dynamics of Contagious Disease Spread". International Journal of Health Geographics, 8:50

[15] Peel Public Health. (2007). "Pandemic Influenza Plan for the Health Sector in Peel Region".4 pages

[16] Tachiiri, Kaoru; Klinkenberg, Brian ; Mak, Sunny and Kazmi, Jamil . (2006). "Predicting outbreaks: a spatial risk assessment of West Nile virus in British Columbia" International Journal of Health Geographics 5:21

[17] Schull, Michael J.; Stukel, Thérèse A.; Vermeulen, Marian J.; Zwarenstein, Merrick; Alter, David A.;. Manuel, Douglas G; 
Guttmann, Astrid ; Laupacis, Andreas and Schwartz, Brian. (2007)."'Effect of widespread restrictions on the use of hospital services during an outbreak of severe acute respiratory syndrome". CMAJ, 176 (13), 1827-32

[18] Thomas Q. Zeng and Qiming Zhou. (2001).”Optimal spatial decision making using GIS: a prototype of a realestate geographical information system (REGIS)" int. j. geographical information science, vol. 15 , no. 4, 307- 321

[19] Watkins, Rochelle; Eagleson, Serryn; Beckett, Sam; Garner, Graeme; Veenendaal, Bert; Wright, Graeme and Plant, Aileen. (2007). "Using GIS to create synthetic disease outbreaks" BioMedical Central Information and Decision Making Vol $7: 4$

[20] World Health Organization. (2009). "Interim planning considerations for mass gatherings in the context of pandemic (H1N1) 2009 influenza”. 9 pages.

[21] Whole of Society Pandemic Readiness. Who guidelines for pandemic preparedness and response in the nonhealth sector". 18 pages.

[22] Noce, A. A., M. C. Otterstatter, et al. (2011). "Decline of Influenza Mortality in Canada since the Spanish Flu." Global Journal of Health Science 3(2): 29-39.

[23] Ontario Ministry of Health (2013). "Ontario Health Plan for an Influenza Pandemic 2013." Retrieved May 20, 2015.
[24] Abbas, S. and e. al. (2009). "GIS-based disaster management: A case study for Allahabad Sadar subdistrict (India)." International Journal of Management of Environmental Quality 20(1): 33-51.

[25] ESRI (1999). "GIS for Emergency Management." ESRI White Paper.

[26] Goodchild, M. F. (2006). "GIS and disasters: Planning for catastrophe." Computers, Environment and Urban Systems 30(2006): 227-229.

[27] Gordon, J. (2002). Comprehensive Emergency Management for Local Governments: Dimystifying Emergency Planning, Rothstein Associates Inc.

[28] Jaiswal, R. K., S. Mukherjee, et al. (2002). "Forest fire risk zone mapping from satellite imagery and GIS." International Journal of Applied Earth Observation and Geoinformation 4(1): $1-10$.

[29] Longley, P. A., M. F. Goodchild, et al. (2005). Geographic Information Systems and Science, Wiley.

[30] Prizzia, R. (2009). "The role of GIS in emergency management." Public Manager 38(3): 63-65.

[31] Kwan, M. and J. Lee (2005). "Emergency response after 9/11: the potential of real-time 3D GIS for quick emergency response in micro-spatial environments." Computers, environment, and urban systems 29(2): 93-113. 